\title{
REPRESENTACIONES SIMBÓLICAS DEL GÉNERO EN MANABÍ-ECUADOR
}

\section{Symbolic representations of the gender in Manabí-Ecuador}

\author{
Artículo de investigación científica y tecnológica \\ DOI: https://doi.org/10.21501/23461780.3578
}

Recibido: 10 de agosto de 2019 / Aceptado: 16 de enero de 2020 / Publicado: 30 de abril de 2020

\section{Fanny TubayZ."}

${ }^{a}$ El artículo derivado del proyecto de investigación El género como estructura social en el artesanado ecuatoriano y portugues, inscrito al grupo de investigación intercultural INTER de la Universidad Nacional de Educación a Distancia, UNED, España.

* Magíster en Educación Intercultural. Candidata Doctoral UNED- España -Programa de Doctorado en Educación. Contacto: fannytubay@hotmail.com ORCID: http://orcid.org/0000-0002-9156-0956 


\title{
Resumen
}

Los estudios de género en la provincia de Manabí- Ecuador son casi inexistentes y escasamente planteados en los ámbitos sociales y políticos de la región, en consecuencia, la discusión, de por sí limitada, recae en discursos y prácticas encriptadas en estructuras sexistas que reproducen mensajes sobre sus representaciones sociales en esa provincia. Por ello, se analizan los símbolos y discursos para conocer esa realidad, desde la perspectiva de un grupo de habitantes conectados directa e indirectamente con el contexto. Se aplica una metodología cualitativa con herramientas etnográficas basadas en entrevistas y análisis de imágenes. Las representaciones simbólicas nos muestran estereotipos y roles interiorizados en las prácticas desiguales y violentas, en una población fuertemente abrazada a la identidad cultural de su pueblo, en la que se encuentra naturalizado el poder masculino sobre lo femenino.

\section{Palabras clave}

Estereotipos; Estudios de género; Identidad cultural; Manabí; Roles interiorizados; Representaciones simbólicas.

\begin{abstract}
Gender studies in the province of Manabí- Ecuador, are almost nonexistent and scarcely raised in the social and political arenas of the region. Consequently, the discussion, which is limited in itself, falls on speeches and practices encrypted in sexist structures, reproducing messages about their social representations in that province. Therefore, the symbols and speeches are analyzed to know that reality, from the perspective of a group of inhabitants directly and indirectly connected as the context. A qualitative methodology is applied with ethnographic tools based on interviews and image analysis. The symbolic representations show us stereotypes and internalized roles in unequal and violent practices, in a population strongly embraced by the cultural identity of their people, in which the masculine power over the feminine is naturalized.
\end{abstract}

\section{Keywords}

Cultural identity; Gender studies; Internalized roles; Manabí Stereotypes; Symbolic representations. 


\section{Introducción}

\section{Antecedentes históricos de los papeles de género en Manabí}

Los estereotipos de género en Manabí tienen su origen en la influencia de las culturas que se asentaron en la costa ecuatoriana, transformando las formas de vida las familias y las sociedades, y aceptando un aparente orden social normativo. Estas prácticas culturales, por un lado, derivadas de las culturas Manteña, Chorrera, Machalilla, Guangalam Bahía, Chirije, Jama Coaque I, II, Milagro, Tejar, Huancavilca (Regalado, 2018), distribuían actividades en función del género. Los hombres se dedicaban a la agricultura y la pesca, y la mujer a las actividades de cuidado y atención en el hogar (hijos, alimentos y vestimentas). Por otro lado, la influencia de la época colonial y la republicana sostuvo ciertos patrones sociales que prevalecen actualmente y son los que han construido el escenario y los personajes de esta zona (mujer y hombre montubio). Estos sucesos dieron paso a que Manabí sea un emplazamiento de contrastes socioculturales, enraizados y abrazados a una identidad que dice llamarse propia.

Los personajes manabitas están pensados sobre la norma biológica del sexo y de construcciones culturales, para establecer ideas estereotipadas de género (femenino y masculino) alrededor de "fuerza-debilidad" y "casa-calle" (Tubay, 2019). Asignando a cada categoría roles justificados en la tradición que fueron estableciendo los límites para ser mujer u hombre y comportarse correctamente en las esferas públicas y privadas. Para hablar del montubio ${ }^{1}$ como personaje, recordamos que, históricamente lo masculino ha sido descrito en función de unas particularidades machistas, aceptadas e interiorizadas por la sociedad como un rasgo de identidad cultural. Del lado femenino, la condición pasiva y reducida a la obediencia al sistema patriarcal (Federici, 2004), ha sido la constante para desarrollarse como mujer (esposa o pareja de un hombre), ama de casa y cuidadora del hogar.

La palabra castiza es "montubio" (del latín montis = del monte, y del griego: hios = vida). Pero De la Cuadra (2004) la hizo derivar del latín "vita" y la transformó en "Montuviio". 
De la Cuadra (2004), en su obra Los Sangurimas, relata brevemente la situación del hombre, pero también el rol de la mujer en la campiña Manabita. Así, cuenta que su personaje principal (Nicasio Sangurima), se había casado tres veces y había tenido un sinnúmero de hijos que estaban regados por todas partes, en los alrededores y muy lejos. Para el personaje tener más de una conviviente era un hecho normal, y mucho más tener hijos, porque eso proyectaba y garantizaba su virilidad y descendencia. De la Cuadra (2004) narra que a Nicasio en alguna ocasión le preguntaron cuántos hijos tenía, a lo que él respondía: "Si estaba a mano una mazorca de maíz, la mostraba al preguntón. Cuente los granos, amigo. ¿Ya los contó? Ese es el número" (2004, p.33).

Esta realidad del personaje no se agota en la obra literaria, sino que es constante en el imaginario para demostrar el grado de virilidad masculina y su importancia en los rituales de emparejamiento, pues el número de hijos no solo reafirma un estereotipo de fuerza para el trabajo fuera de casa (Tubay, 2019) y poder sexual, sino que propone un prototipo de pareja ideal que sostiene los demás aspectos de las relaciones sociales. La mujer, de su lado, desde el rol reproductor dentro del hogar, concibe hijos, maneja los alimentos y proporciona cuidados a los miembros de la familia. Parcial o totalmente esas costumbres fueron transmitidas e imitadas por las siguientes generaciones, quienes reafirman asimetrías sociales que recaen en formas de dominación masculina y cruzan el umbral de la violencia simbólica (Bourdieu, 1996), para persistir en espacios que responden a patrones culturales de comportamiento machista y que tienden a naturalizar otras formas de violencia más allá de lo físico y la agresión sexual (Viteri, 2016). La violencia, a la par que los estereotipos, no es genética, sino también transmitida de una generación a otra por las conductas aprendidas y por lo que ha quedado como herencia de nuestros antepasados (Lucas Meza y Mestre Gómez, 2018), y afecta a todas las culturas y grupos sociales indiferentemente del status socioeconómico (Gómez Mieles y Román Cao, 2018) no solo en Manabí, sino en todo el mundo.

En suma, la cultura machista naturalizada en nuestro medio aún sigue arraigada e influye en el comportamiento de los habitantes, quienes no perciben en su normalización ninguna forma de opresión, sino que, como afirma LéviStrauss (1985), esta se encuentra aparentemente yuxtapuesta o superpuesta 
a la vida, y es capaz de sustituir, utilizar y transformar nuevos ordenes sociales. La historia de esta provincia impronta unos papeles de género, marcados por la tradición familiar y social, en la que el sexo es el determinante del destino de mujeres y hombres. Por ese motivo, las representaciones analizadas tienen cimientos en una imagen reproducida en un discurso de tradiciones y lenguaje simbólico al que nos permitimos prestar atención y dejarlo hablar (Jung y Kerényi, 2004), por medio de un arquetipo construido y desdibujado desde los imaginarios propios y ajenos que, a manera de estereotipos y prejuicios, cimentan lo femenino y lo masculino, bien sea para desfavorecer o privilegiar. A partir de ese lenguaje habituado en el imaginario social, este trabajo obtiene resultados desde dos marcos referenciales. Uno representado por los códigos simbólicos femeninos y masculinos, característicos del identitario cotidiano. $Y$ un segundo, descrito a partir de los colaboradores como un todo general 0 plural para responder a una identidad impuesta que los engloba en cada una de sus categorías en el sistema capitalista patriarcal (Federici, 2004).

Si bien se trata de prácticas normativas machistas, para algunos habitantes estas representan un motivo histórico y cultural que dice diferenciar a un manabita de cualquier otro ecuatoriano. Por medio del reconocimiento de la alteridad, se autoidentifican con un estereotipo de nobleza, valentía y trabajo para el caso de lo masculino. Y con estereotipos de belleza y cualidades positivas para ser consideradas buenas madres y amas de casa, en el caso femenino. Estas formas de autoidentificación, emancipación y reconocimiento sintetizan una plurifemeneidad y plurimasculinidad en categorías estándares que escapan de la realidad y de los nuevos modelos de construcción femenina, masculina u "otros géneros" (Butler, 2007). En tal sentido, la identidad manabita se presenta como metáfora para reducir a la cultura, haciendo necesario abordar esta problemática como tema emergente en los estudios de género en Ecuador.

Por esos motivos, acudimos a teorías modernistas femeninas y al marxismo feminista para centrar el análisis desde esos enfoques y hablar de la mujer y del hombre manabita desde las ideas que se construyen alrededor de sus representaciones, de manera individual y colectiva. Pues son estas, las que "dan forma a las categorías y estereotipos que a modo de símbolos, arqueti- 
pos y mitos, recrean las expresiones del imaginario social, dando forma a las imágenes" (García Peña, 2012, p. 133). De ahí que dialogar epistémicamente desde esos aportes con autores como Jung (1991), Bourdieu (1996) y García Peña (2012), y desde la crítica feminista "que no se basa en el estudio de la mujer, sino en el análisis de las relaciones de género y del género como principio estructural de todas las sociedades humanas" (Moore, 1991, p. 9), resulta primordial para interpretar los significados de las representaciones sociales, y la forma en que influyen y tienen cabida en la dinámica ciudadana manabita estas representaciones que invisibilizan, folclorizan y reafirman la desigualdad y la injusticia social.

\section{Método}

La metodología cualitativa nos ofrece "una variedad de materiales, como entrevistas, experiencias personales, observaciones, imágenes y sonidos" (Flores, Gómez y Jiménez, 1999), En consecuencia, en este estudio utilizamos entrevistas semiestructuradas e imágenes para interpretar desde la perspectiva de sus miembros (Guber, 2019), los arquetipos que derivan de hechos sociales y culturales en un grupo de mujeres y hombres sienten, piensan, hacen la diferencia y tejen la vida (Guerrero, Ferraro y Hermosa, 2016) en la provincia de Manabí. Por consiguiente, acudimos a la etnografía como método de investigación para expresar en palabras y en prácticas el sentido de la vida, la cotidianeidad, los hechos extraordinarios y el devenir (Guber, 2019) de mujeres y hombres que en su diario vivir encarnan prácticas desiguales a causa de unas representaciones sociales enmarcadas en estereotipos de género. De ese modo, ofreciéndonos la etnografía medios inmejorables para conocernos (Guber, 2019) y reconocernos en la diversidad, las dos herramientas derivadas de la etnografía (entrevistas e imágenes), nos abren paso a investigar la realidad, presente o pasada del contexto escogido, por medio de un lenguaje que aprovecha todas las posibilidades para observar y establecer un diálogo (Mundó, 2015) entre lo observado y expresado. 
La decisión tanto metodológica como la elección de los colaboradores se definió alrededor de un proyecto de investigación doctoral que analizaba la perspectiva de género en Manabí. A la luz de ese trabajo, las representaciones sociales que proyectaban los discursos y las imágenes alrededor merecerían un estudio específico que permitiera conocer los imaginarios sociales para lo femenino y lo masculino en esta provincia. En ese sentido, las entrevistas semiestructuradas fueron realizadas a veinte personas que decidieron colaborar autónomamente. Y se llevaron a cabo como conversaciones entre pares, tratando de sintonizar los significados producidos interactivamente con la dinámica emocional dentro de la entrevista (Ellis \& Berger, 2003). Para diferenciar e interpretar los resultados, etiquetamos a los colaboradores en dos grupos. En el primero, agrupamos a quienes nacieron en Manabí, y en el segundo, a aquellas personas que vivían o estaban de paso en la provincia y que eran externos al área geográfica. El sentido de entrevistar a dos segmentos de población se fundamenta en la idea de observar desde la pertenencia a una región y desde la convivencia en un rol de invitado externo, que observa cómo se proyecta y construye una identidad desde los bordes.

De su lado, la selección de imágenes fue tomada de sitios de internet: webs institucionales, de publicidad en revistas físicas o electrónicas. Para su elección se utilizaron descriptores en buscadores bajo las denominaciones "mujer manabita", "hombre manabita", "montubio manabita". Estas imágenes son el resultado de esas búsquedas en el año 2017, de modo que muestran los símbolos visibles que identifican a las mujeres y hombres, siempre desde una aproximación parcial y desde una singular manera de concebir el orden simbólico de la realidad (Mundó, 2015). En ambos casos, para el análisis se toman como base fundamentos teóricos de los estudios de género y de las representaciones simbólicas, a través de autores que dialogan y ponen en debate enfoques que discuten, reafirman o reconstruyen ideas y conceptos.

Tabla 1. Tipos de entrevistas

\begin{tabular}{|c|c|c|}
\hline Tipos de entrevista & Código & Origen \\
\hline $\begin{array}{l}10 \quad \text { Entrevistadas/os } \\
\text { nacidas/os en Manabí }\end{array}$ & M1 al M10 & Cantones: Portoviejo, Santa Ana, Manta, 24 de Mayo, Junín \\
\hline $\begin{array}{l}10 \text { Entrevistados de } \\
\text { diversos orígenes }\end{array}$ & E1 alE10 & $\begin{array}{l}\text { Otras provincias del Ecuador: Pichincha, Guayas, El Oro, Loja. Países: España, } \\
\text { Venezuela, Colombia }\end{array}$ \\
\hline
\end{tabular}


En la tabla 1 los códigos del 1 al 10 con la inicial M, corresponden a las personas que nacieron en Manabí. Y los codificados del 1 al 10 con la letra $E$, a un grupo de personas de diversos orígenes (otras provincias del Ecuador y otros países). Los resultados plantean cuestionamientos que indagan ¿con qué símbolos se identifica al Manabita?, ¿cómo define al habitante de Manabí? 0 ¿qué representa la mujer y el hombre en Manabí? Estos datos se formulan en correspondencia con los diversos aportes que sustentan un trabajo de campo que tuvo como prioridad un acercamiento a la realidad del entorno.

\section{La construcción sociocultural de la mujer y el hombre manabita}

Según los datos de INEC (2010), la provincia cuenta con 1.369.780 habitantes, cuya edad promedio es relativamente joven (28 años). El 49,7\% son mujeres y el 50,3 son hombres. También se conoce que 346.118 personas de la población son mujeres que se encuentran en edad reproductiva ${ }^{2}$. La tasa de escolaridad femenina es de 8,6\%, por encima de una masculina de 8,3\%, es decir tres puntos más alta que la de hombres, pero no muy alejada de la brecha de desigualdad escolar en el país. Por su parte, la población económicamente activa es más elevada en los hombres que en las mujeres. Esta categoría disocia una realidad segmentada en espacios diferentes para lo femenino y masculino. De una mano, la mayoría de los hombres se destina a la agricultura y a trabajos que utilizan la fuerza fuera de casa. Mientras que a las mujeres se les asignan funciones del hogar 0 al comercio informal, consideradas de menor importancia. Eso también lo sostiene Tubay (2019), quien afirma que se trata de una sustantividad global alineada en función de dos protocategorías (casa y calle). La calle para lo masculino y la casa para lo femenino.

En cuanto a la autoidentificación, el INEC revela que el 69,9\% de la población se considera mestiza y apenas un $19,2 \%$ se reconoce como montubia ${ }^{3}$, lo que nos lleva a pensar que no toda la población se identifica como montubia

\footnotetext{
Mujeres de 15 a 49 años (INEC, 2010).
}

Cifras del INEC -Instituto Nacional de Estadísticas y Censos. Censo poblacional del año 2010. Se pueden revisar en: http://www.ecuadorencifras.gob.ec/wp-content/descargas/Manu-lateral/Resultados-provinciales/ manabi.pdf 
pese a que en el imaginario colectivo la provincia es reconocida por un estereotipo identitario bajo esa figura, sometiendo a la población a características rígidas que generalizan a todos bajo patrones similares y equivocados. En consecuencia, se trata de una población estigmatizada, cuyos matices sociales responden a mensajes que a menudo se transmiten de manera implícita a través del lenguaje y otros símbolos (Lamas, 1996) en diferentes entornos y situaciones (étnicas, de género, de clase social, economía, cultura y economía). Estos datos ponen en valor una diversidad que trasciende lo étnico y recoge resultados de la constante trasformación y la ascensión de las culturas híbridas (Canclini, 2017) en la construcción de sociedades interculturales. Por ende, hablar de una identidad fija en Manabí resulta contradictorio, porque al contar una población enriquecida por la diversidad de orígenes y bagajes culturales, se pone de relieve el aporte al desarrollo económico, cultural y social de unos grupos caracterizados por la pluriculturalidad de sus entornos multiculturales. A eso se refiere Nash (2001) cuando afirma que en los contextos actuales de globalización, el reconocimiento del multiculturalismo permite la definición del concepto cultura en términos de diversidad y de identificación de la variabilidad cultural. Esa diversidad cultural que también es de género permite reafirmar que la sociedad es inevitablemente un mundo de significados ${ }^{4}$ (Connell, 2002) interpretaciones y dimensiones colectivas, en la que mujeres y hombres proyectan realidades distintas, en confrontación con reglas establecidas en una cultura rutinizada y habitualizada (Dietz, 1999) donde se espera que las personas actúen conforme a los estereotipos.

Acorde con García Peña (2012) las “imágenes simbólicas que se elaboran como un ejercicio de la imaginación, se ligan a la representación a través de los datos sensibles que las constituyen, y a la memoria porque recurren a las experiencias pasadas para crearse" (p.134). En tal sentido, esto es una realidad en los imaginarios estereotipados de género en Manabí, dado que la "invención de tradiciones" (Hobsbawn y Ranger, 2002) en ese espacio responde a un legado histórico que desde el pasado hasta la actualidad continúa reproduciéndose en sus prácticas más hegemónicas.

Traducción propia al español de Gender Short Introductions. 
La construcción de una visión despojada de ideas preconcebidas y de conceptos que justifican la igualdad de desiguales (Quijano, 2003) muestran cómo a través de imágenes e interpretaciones estereotipadas se reproducen y conciben otros eslabones y subcategorías dentro y fuera de Manabí. Muchas de estas se hacen visibles o perceptibles en el lenguaje masculino o masculinizante (Romão, 1989) que se utiliza para hablar del propio "género", y que colocan a lo masculino en estados superiores a lo femenino (Lorber, 2009). Ya sea porque "algunos mecanismos lingüísticos acentúan la invisibilización de las mujeres y la valoración asimétrica de lo que está asociado con lo masculino y lo femenino" (Do Mar Pereira, 2012, p. 82) o porque es una naturalización compleja para deconstruir y despatriarcar.

Estas contradicciones socioculturales de la cosmovisión local implican una sentencia y un destino proclamado, que más allá de ser discutido, es alagado como un pensamiento cuya noción universal ignora las diferencias y la diversidad de la experiencia colectiva (Nash, 2001). Los enunciados de belleza, fuerza 0 amabilidad que caracterizan al Manabita no permiten problematización o "ser capaces de aislarlos de otros fenómenos de sentido y fundamentar su existencia particular" (García Peña, 2012, p. 127), sino más bien, encapsular la identidad como una receta estándar. Esa perspectiva simbólica representa una entrada enigmática y sugerente al mundo de los significados humanos (García Peña, 2012), agrega etiquetas con conceptos de belleza, hospitalidad que juegan peligrosamente en las fronteras preferenciales de un imaginario central (masculinidad) construido históricamente como cimiento (Munizaga, Araya y Rojas, 2014) y como orden simbólico y social. Otro ejemplo se describe en la representación femenina y masculina en Manabí (mujeres tejiendo el sombrero de paja toquilla, cerca de las montañas y el campo, y hombres usando el machete en el agro o pescando) (participante M2). En el primer caso, reafirmando la pertenencia femenina al hogar y a la sutileza, en esferas del espacio privado. $Y$ en el segundo, asentando la fuerza masculina en los imaginarios externos al hogar, en arduas jornadas laborales dominando el espacio público (Tavares, 2012; Tubay, 2020). Eso no solo solapa los espacios acordes con el género y fortalece un imaginario de "hombre trabajador y aguerrido, que no 
se deja vencer fácilmente y a una mujer hospitalaria y la vez sencilla" (participante E1), sino también una imagen masculina jolgoria que combina violencia y comedia simultáneamente.

\section{Representaciones sociales}

Las representaciones sociales son el seno gestatorio de las imágenes primordiales, común para todos los seres humanos (Giraldo, 1961), su orden colectivo obedece a un pensamiento social (Durkheim, 1912), en el que individuos diferentes comparten también pensamientos diferentes, más allá de las representaciones individuales que tengan (Pérez, 1999). Por esa razón, proyectan señales individuales o colectivas a través de símbolos y arquetipos, que más adelante se convierten en estereotipos. Esas representaciones son,

el producto de una inmensa cooperación extendida no sólo[sic] en el tiempo, sino también en el espacio; una multitud de espíritus diferentes que han asociado, mezclado, combinado sus ideas y sentimientos para elaborarlas; amplias series de generaciones que han acumulado en ellas su saber. Se concentra en ellas, un capital intelectual muy particular, infinitamente más rico y complejo que el individual (Pérez, 1999, p.14)

Así encontramos que la naturaleza del pensamiento social es la comunicación por símbolos, que además se encuentra basada en el funcionamiento mental por medio de la actividad simbólica (señales, interpretaciones) (Pérez, 1999), y de discursos que mutan, se personalizan y se atan a conformaciones colectivas del imaginario cultural (García Peña, 2012). Para este autor los símbolos son:

esas pequeñas unidades que poseen una gran capacidad concentradora de energía significativa, que migran de una época y de un contexto a otro, permaneciendo asombrosamente estables a lo largo de la historia de la cultura, y al mismo tiempo, adaptándose a una gran y diversa posibilidad de contextos semióticos (García Peña, 2012, p. 126).

Estas representaciones sociales en Manabí giran en torno a la elaboración de conceptos y elementos ilustrativos originados en un momento cultural e histórico impreciso, en el que imágenes de féminas con largos y anchos vestidos, y 
de hombres con machete en mano afianzaron un fenómeno de índole colectivo, cuyo acervo de experiencias fue transmitido generacionalmente dentro de su estructura social (García Peña, 2002). Eso dio paso sobre todo a que colectivamente se conviertan en las víctimas favoritas de la dominación simbólica, y en agentes oprimidos de las clases dominantes (Bourdieu, 1996), para edificar idearios femeninos y masculinos, como estrategia para sostener los modelos patriarcales y funcionales al sistema capitalista (Eisenstein, Sefchovich \& Mastrangelo, 1980).

El concepto arquetipo en las representaciones colectivas (Jung, 1991), propone elementos que explican la generación de una serie de imágenes mentales, desarrolladas de forma muy similar por diferentes personas de diferentes culturas. Por ejemplo, los arquetipos de la madre, el hombre sabio, el héroe o la doncella, propuestos por Jung (Gratacós, 2017), son los que definen estereotipos y roles más adelante. En Manabí, eso ocurre alrededor de características generales que son dadas y recibidas con beneplácito por sus habitantes: "los manabitas son amables, la mujer del campo cocina bien, el manabita es bravo/valiente" (participante E5). Por ello, no resulta extraño que en la provincia ese sistema dinámico de símbolos, arquetipos y esquemas tiendan a constituirse en relatos (Durand, 2004), y verdades elaboradas, incidiendo en cómo las personas se ven a sí mismo y cómo son percibidos en el mundo social. La impronta que confieren las representaciones simbólicas, maximizan su rol como ideologías y normas de justificación (Winker \& Degele, 2011), para perpetuar la violencia o para en casos de ausencia de poder, recuperarla, restaurarla y reclamarla (Carabí \& Armengol 2008). Y para enraizarse en las profundidades del inconsciente humano, dada su capacidad para arrastrar y condensar la experiencia colectiva (García Peña, 2012).

Finalmente, notamos que en Manabí las representaciones sociales de la imagen y arquetipos recurren a lo semiótico para salvaguardar pensamientos y conceptos basados en la tradición y en la justificación heteronormativa, puesto que, en los procesos comunicativos representados en cosas y actividades interpretativas, como lo afirma Lacan, citado en Butler (2007), lo semiótico 
está siempre supeditado a lo simbólico. Es decir que los signos 0 señales que recrean imágenes conectadas a códigos determinan otras formas de comunicación y de creación de representaciones simbólicas. Y, pese a que lo semiótico es un ideal emancipador, un tipo de lenguaje que nunca se puede conservar de manera coherente, pues reafirma la tesis constantemente maleable de imágenes que se desprenden de su experiencia (Butler, 2007), en Manabí por causa del amor a las costumbres (Cusme, 2012) persiste por mantenerse inmóvil.

\section{Símbolos y arquetipos en Manabí}

Las figuras 1 y 2 muestran a la mujer en espacios de dominio privado (cerca del mar o la campiña), aun cuando la simbología planteada da cuenta de una objetivización femenina que explica cómo es el imaginario femenino en esa provincia: arquetipo de mujer alegre ya sea bailando o realizando tareas de ayuda en el agro. La figura 2 expone el papel femenino como medio de publicidad de una feria ganadera realizada en el Cantón Chone, esta tiene una representación que etiqueta a la mujer chonera con cánones de belleza deseables para las sociedades capitalistas patriarcales (Federici, 2004).

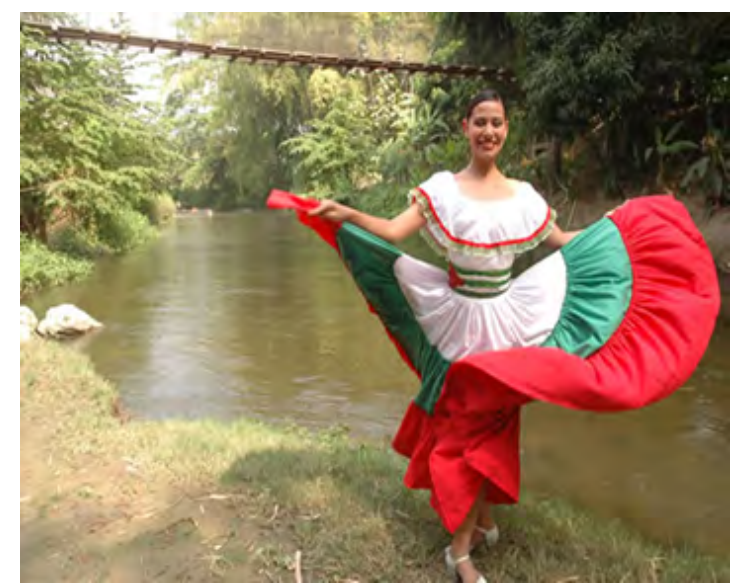

Figura 1. Mujer Manabita bailando. Tomada de: Gobierno Provincial de Manabí www.manabi.gob.ec 


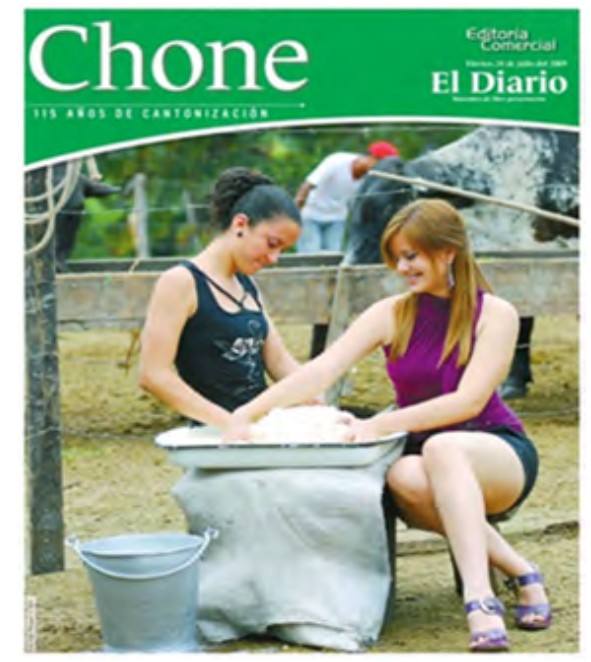

Figura 2. Chone. Tomada de: Diario Manabita-Ecuador https://issuu.com/telandweb/docs/chone-especial

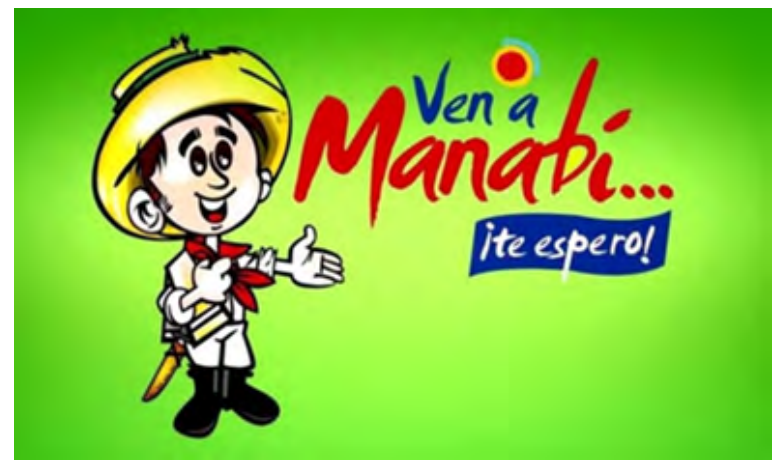

Figura 3. Manabi destino turístico. Tomada de: Gobierno provincial de Manabí www.manabi.gob.ec

En la figura 3 aparece el campesino manabita que promueve el Gobierno Provincial en los medios de comunicación, se trata de un hombre vestido de hilo (pantalón y camisa), machete, sombrero y botas, dedicado a la agricultura y ganadería (Puga, 2012). Esta figura masculina es la que en la región ostenta patrones de poder (Quijano, 2003) con las mujeres de la zona. Pese a que en las características que lo describen resaltan la humildad y la alegría del personaje, también se destaca su virilidad, fuerza para trabajar la tierra y para perpetuar el poder económico en sus familias. 
La figura 4 acentúa una figura androcentrista, mostrando a una mujer parada sobre un caballo y ayudada por un hombre. Arquetípicamente representa uno de los principales roles masculinos, si nos centramos en que sostiene lo femenino y la protege de peligros, valiéndose de su fuerza física y del dominio de su poder.

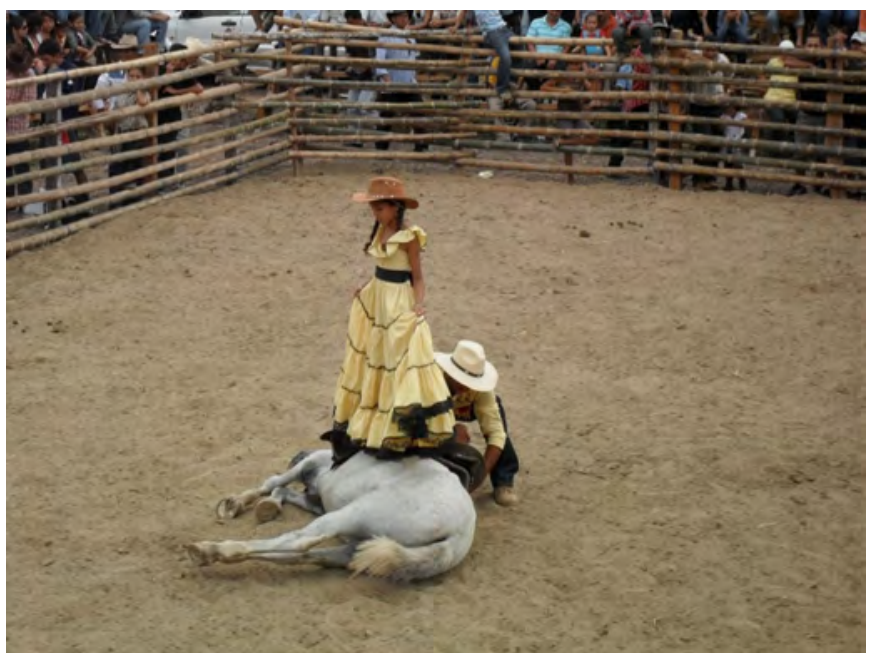

Figura 4. Rodeo Montubio en Olmedo. Tomada de: Blog ManabíEcuador http://actividadesculturalesmanabi.blogspot.com/2010/08/ rodeo-montubio-en-olmedo.html

\section{El hombre montubio de Manabí}

El personaje montubio como construcción simbólica está ligado a connotaciones que además de su reducción, lo obligan a forjar y a mantener una identidad prístina, violenta, pero a la vez jolgoria en el sector rural y pesquero de la provincia. Garay Arrellano (2010), afirma que el personaje es un mestizo descendiente de las antiguas culturas aborígenes del litoral, es aculturado como lo son los habitantes de las ciudades y pueblos que están a la orilla del mar. También lo describe rudo, rústico y montaraz; por ser el hombre del campo, casi ignorante, incivilizado como todo campesino del mundo, solamente dedicado a las faenas ganaderas, a la labranza de la tierra y a la producción agrícola. El montubio es estereotipado como machista, agresivo, humilde como sinónimo de sumisión, y en ocasiones ha sido citado 
y personificado bajo un perfil de abuso y poder sexual en la literatura y en los medios de comunicación. Por ejemplo, en la novela ecuatoriana Sangurimas, se lo describe como un hombre machista y mujeriego, que incluso llega a cometer incesto, como forma natural de posesión de lo femenino en el entorno familiar.

Estas representaciones colectivas muestran un arquetipo de hombre construido desde un androcentrismo que tiene sus bases en el poder, estatus y clase social (Weber, 1978). No obstante, detentan esa estratificación únicamente dentro de sus imaginarios, porque externamente son encasillados en la figura del pescador, agricultor, al hombre montubio perteneciente a un imaginario periférico (Munizaga, Araya y Rojas, 2014), vinculado con el control de la tierra, de los animales, del hogar, del dinero y de la familia en el campo o en el mar.

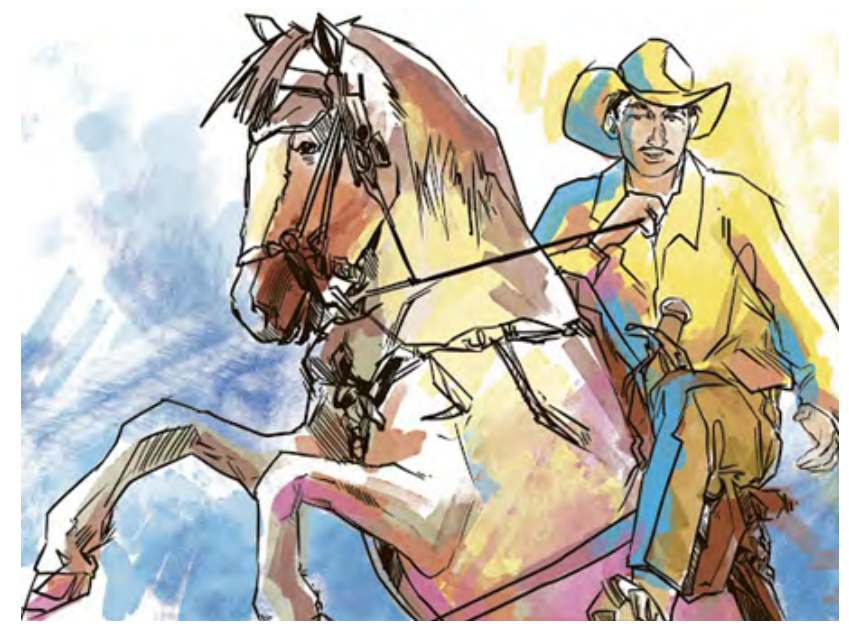

Figura 5. La vestimenta del Montubio es un Ícono de identidad. Tomado de: $h$ ttp://www.eldiario.ec/noticias-manabi-ecuador/400672la-vestimenta-del-montuvio-es-un-icono-de-identidad/

De lo expuesto se desprenden otras representaciones que acogen, entre otros, a hombres subordinados, negros o bajo la dominación colonial (Lorber, 2009), enfrentados por la diferenciación de la masculinidad marginalizada a causa del origen, del poder y de la feminidad en su propia cultura (Villavicencio, 2013), propiciando otras escalas de discriminación para esa categoría binaria. 


\section{Imaginarios y representaciones femeninas y masculinas}

El sistema social y económico del contexto, por un lado, ratifica imaginarios de "hombres muy trabajadores y aguerridos" (participante E5), y hábiles para tomar decisiones en las atmósferas que los rodean y sobre quienes están bajo su dominio - la familia y otros hombres con menor poder - (De Dios-Vallejo, 2014). Y, por otro lado, los torna en arquetipos violentos y machistas que no son percibidos como tal, pues responden al orden simbólico de razón y obediencia, constituido en expectativas colectivas y en creencias socialmente inculcadas (Bourdieu, 1999). Todo esto juega a favor de unos arquetipos femeninos y masculinos construidos con base en imágenes desplegadas con regularidad en espacios sociales y discursivos (García Peña, 2012) que colocan a Manabí en un contexto folclórico por causa de una cultura inmóvil, cuyos personajes permanecen estancadosy estereotipados en el tiempo para gustoy satisfacción de una memoria colectiva que estrictamente oprime a mujeres, pobres, a colonizados, a etnias estigmatizadas y otros sectores menos beneficiados en la sociedad (Bourdieu, 1996). De ese modo, los consagra por vía simbólica en condiciones desiguales socialmente (Sacaluga, 2013) y alrededor de unos distintivos concentrados en significados (García Peña, 2012), los cuales asientan que "ser mujer o ser hombre significa también estar sujeta 0 sujeto a un conjunto de prescripciones normativas" (Bedia, 2005, p.18).

Vale mencionar también que la disparidad por género, etnia o clase social tienen características que no obedecen únicamente a la estructura social, sino a raíces más profundas, encarnadas como normas de vida para sus habitantes. Muchas de esas costumbres están ligadas a la imaginación moral (Geertz, 1983), con un gran peso e influencia en la vida de estas familias manabitas. Los discursos que circulan con frecuencia se fundamentan en distintas creencias religiosas que refuerzan el miedo y la obediencia como dispositivos de dominación.

Lo femenino, pese a que es objetivizado sexualmente como mujer y madre, debe reprimir y condicionar su lenguaje desde una postura moralista circunscrita en la esfera privada; para ella hablar del cuerpo o sexo en público es mal visto y condenado. Esto pese a que en la estructura familiar "llegan a procrear 
entre seis y diez hijos en promedio" (participante M6). Procrean, pero no tienen acceso a planificar la familia o prevenirse de enfermedades de transmisión sexual, porque ese tipo de información es escasa en la casa y en la escuela, y preguntar sobre esos temas es, además, un tabú. № así para los hombres, cuyo estereotipo machista es reconocido en la permisión de ciertas cosas que en la mujer son condenables. Cusme (2012) menciona que el adulterio en los hombres manabitas es concebido y tolerado. Es considerado como una característica que exalta la virilidad y trae orgullo porque así el varón reproduce su casta familiar, y no como un modelo de fragilidad masculina que, a decir por Connell (1995), solo existe en contraste con la feminidad. 0 como lo afirma Scott(2008), evade la represión de los aspectos femeninos, tan comunes entre todos los seres humanos. Para Lorber (2009),

la televisión, el cine, la música, la publicidad, y, por otro lado, los bailes, el teatro y el propio lenguaje habitual, son medios que tienen discursos que abierta y subliminalmente nos dicen algo sobre los cuerpos femeninos y masculinos, deseos sexuales y roles de género (p. 270).

En consecuencia, las formas deliberadas de agresión hacia la cultura montubia y su cosmovisión asaltan el imaginario por medio de contenidos sexuados discriminadores y de un lenguaje patriarcal, evidentemente presente en la recitación de amorfinos, canciones o coplas populares. Así, se puede palpar en los ejemplos propuestos a continuación:

1) El aguacerito manda lo que debemos de hacer, los hombres a trabajar las mujeres a tejer (Extracto de una canción de Rueda Fuente: De Barro - Proyectos Culturales).

2) El que tiene más de una, eso nadie se lo quebranta, si se le muere la yegua vieja, se queda con la potranca (Amorfino del grupo de danza folclórico Los Mentaos de la Manigua, 2011).

Estos fragmentos muestran la antítesis de la mujer cuidadora y del hombre proveedor (Núncio, 2008), distinguiendo la infidelidad, la traición, el poder, la cosificación femenina y las categorías del silencio (Rivera Cusicanqui, 2010), como hechos sociales inherentes al folclor y la alegoría de sus personajes; 
dejando lo montubio atrapado en "identidades creadas mediante normas" que a su vez "dependen de la invocación constante y reiterada de reglas que determinan y limitan prácticas de identidad culturalmente inteligibles" (Butler, 2007, p. 281) interiorizadas por la historia o por la repetición cotidiana de hábitos discriminatorios. En consecuencia, a partir de esos lenguajes comunicativos, surgen imágenes y representaciones que se pasean libre y abruptamente en la cotidianeidad, capaces de condicionar y perpetuar la normalización como un hecho incuestionable, conllevando a mujeres y sobre todo a hombres a ser "prisioneros e, irónicamente, víctimas de la representación dominante" (Bourdieu, 1996, p. 54).

El lenguaje sexista, el silencio y la observación sin acción suelen ser armas poderosas en esta batalla categórica, en la que los símbolos y arquetipos en la vida diaria, en las representaciones publicitarias y en la literatura simbólica, marcan el pulso en pueblo montubio, que entre otras cosas se autodefine como "gente de palabra, firme, seguro, valiente, bohemio, alegre, galante y sobre todo trabajador y solidario" (Puga, 2012, p.17).

\section{Arquetipos y símbolos de Manabí}

Los arquetipos definidos por Jung (1991) son ideas o formas preconcebidas que actúan sobre los individuos determinando sus acciones y comportamientos, y reformulando contenidos del inconsciente del hombre moderno. Otros autores, como Guil Bozal (1999), señalan que estos se asemejan a los productos de la mente del hombre antiguo, pero tienen una fuerza sugestiva muy difícil de desapropiar en el entorno.

En Manabí, esa construcción femenina o masculina, sea por autoidentificación o por alteridad, responde a un grupo de opiniones reproducidas a partir de roles y estereotipos de género, fundados en las costumbres que se han realizado por amor (Cusme, 2012). En ese aspecto, los arquetipos subyacen de una historia heredada y cargada de representaciones físicas, imaginarias y ficticias, cuyos relatos giran en torno a la belleza, la fuerza y el trabajo, en todos los casos como una institución ya delimitada con sus roles y funciones. En 
esos arquetipos que no contienen propiamente el género intrínseco, pero que categorizan y adjudican cualidades de poder sobre unos y otros, encontramos algunos elementos que forman parte de la identidad cultural. Así lo proponen las voces de colaboradores, para quienes la masculinidad está asociada, además de la fuerza, con componentes construidos en la tradición y en el ocio. Un ejemplo de esto es la asociatividad que se le da al aguardiente - Caña Manabita - como algo propio de la masculinidad en la región. Para estas personas, el consumo de la bebida alcohólica está ligada a la violencia y al dominio del hombre en su rol social.

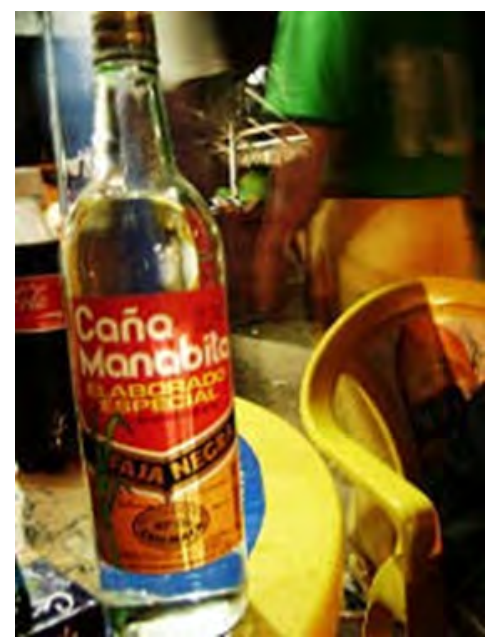

Figura 6. La Caña Manabita. Tomada de: Ecuador Chronicle https://ecuadorchronicle.com/2019/01/19/la-cana-manabita-sevendera-en-el-exterior/

Uno de los hombres convocados en este estudio, relata que el aguardiente de caña está hecho para los machos (participante M6), siendo así que su imagen está posicionada en el imaginario como un símbolo. Para algunos, hablar de la caña, "es hablar de hombres fuertes, la caña es solo para machos" (participante M8). De su lado, este símbolo que es considerado parte de la sustantividad masculina cobra otro significado más allá del propuesto como catalizador social entre hombres, porque implica prácticas que no se dejan percibir con frecuencia, dado que se trata de un elemento de uso y consumo categórico de hombres. Sin embargo, la preparación envuelve saberes populares de un oficio —“la elaboración del aguardiente, guarapo 0 currincho - ${ }^{5}$ que aún es practi-

Destilado final del aguardiente de caña, su nivel de alcohol asciende a los 40 grados. 
cado en cantones como Junín y Santa Ana, en el que muchas veces participan mujeres" (participante M6). La extracción del aguardiente se la realiza artesanalmente a través del trapiche ${ }^{6} y$, aunque en la actualidad se lo industrializa, es común que lo vendan y consuman sin procesar a manera de currincho.

No obstante, como símbolo asociado a lo masculino, sus connotaciones genderizadas-hegemónicas contribuyen al afianzamiento de una cultura machista, en la que la valentía en términos de agresividad y virilidad, como acciones y características propias de un discurso montubio, se reducen a una ilimitada variedad expresiva de producciones imaginativas y de patrones básicos de conducta (Giraldo, 1961), con los lenguajes específicos y simbólicos construidos alrededor de lo femenino influyen, según Lamas (1996), en cómo se piensan 0 se dicen las cosas, las formas narrativas arquetípicas de 0ccidente que dan por sentada la presencia de un protagonista masculino influyen en la forma en que se arman cuentos acerca de las mujeres (p. 3).

Otros símbolos también están presentes en este imaginario manabita, y son "el machete" y "el sombrero", ambos adjudicados al arquetipo masculino. Estos simbolizan "la iniciación del hombre en el trabajo duro, las largas horas de sol o de lluvia en el agro, la fuerza que se necesita para abrir caminos, cortar un racimo de plátano o incluso como arma de pelea" (participante M10).

La relación hombre-machete-sombrero versus mujer-machete-sombrero, está diferenciada nuevamente por el campo, la casa, la sutileza y la fuerza. La distribución por género deja ver que las mujeres trabajan en el agro con machete y sombrero en faenas de ciclo corto, mientras que el hombre en jornadas más extensas, expuestos a actividades que requieren fuerza y comercialización a otra escala y en mercados mayores.

Se pudo conocer además que, en el caso de los sombreros, estos son elaborados por mujeres ya sea para uso femenino o masculino, lo que varía en ese proceso es la materia prima y la calidad. Por ejemplo, para los hombres se usa en el tejido hebras de paja más gruesas y resistentes (para protección del sol y la lluvia). Y en el caso de las mujeres, hebras más finas y delicadas,

${ }^{6}$ Mecanismo de producción del aguardiente puro de caña. Maquinaria rústica artesanal potenciada por la fuerza de un burro. 
que además sirven como complemento decorativo con la vestimenta, dado que su permanencia en el agro es parcial. En cambio, el machete, que junto con el sombrero es el complemento de la vestimenta del hombre montubio, ha sido fabricado con las mismas características para mujeres y hombres. Si bien no hay distinción en ese proceso, si la hay en cuanto a quienes hacen uso del machete cuando está nuevo. En ese caso, los hombres son quienes lo utilizan primero, y cuando ya está desgastado lo usan las mujeres (participante M7), la justificación se centra en que cuando están nuevos pueden ser muy peligrosos.

Por otro lado, en cuanto a los arquetipos encontramos - el ideal de pareja femenina de origen manabita - enfáticamente señalado como un patrón conductual deseable en el modelo de familia para los hombres ecuatorianos.

Aquí se afirma que el prototipo femenino de la provincia es un "referente para los hombres en el país" (participante E10). Esto se convierte en un hecho que cosifica lo femenino, pues comprime a todas las mujeres en un solo ideal (buena mujer, esposa, madre y cuidadora del hogar). Así lo detalló un participante:

(E5): Casarse con una manaba es el sueño de muchos hombres.

¿Por qué?

(E5): Son tucas ${ }^{7}$ (risas) guapas, saben cocinar y son muy de casa. $¿$ ¿Conoces a muchos hombres casados con una mujer Manabita?

(E5): Sí, un amigo que es militar, dos primos y así otros panas más. ¿Yamigas que se han casado con hombres de Manabí, conoces?

(E5): ¡No! Ahí si me la pones difícil, no conozco.

Los aportes de esta persona se basan en un estándar de belleza física de tipo eurocentrista, compaginado con las habilidades desarrolladas imaginariamente para los cuidados maternales y del cuidado del hogar. Esta aproximación deja percibir uno de los cometidos del androcentrismo en su afán de proveer a los hombres (consumidores-admiradores), una vida familiar que le permita trabajar y, por consiguiente, ir alcanzando logros en su ascenso de vida. Pues en un entorno capitalista, trabajo, casa, carro y mujer "bonita" (participante M9), equivale a tener una vida exitosa.

${ }^{7}$ Descripción del entrevistado: mujer fuerte con buenas piernas, ni flaca ni gorda, pero sobre todo fuerte. 
Otro de los colaboradores masculinos indica también que "a los hombres de afuera les gustan las mujeres manabitas, costeñas". Él cree que a la mujer le gustaría casarse con alguien de afuera que no sea de Manabí, "porque puede darle otra vida, en la ciudad y con cosas que no hay en el campo" (participante E4). Eso se justifica, según otros colaboradores, en varias circunstancias y razones, por ejemplo, cuando afirman que conocen "mujeres que se han casado o se han ido con el técnico que construyó la carretera, o el profesor que vino a dar clases" (participante M6), o también por "algunas chicas que vinieron a ser buscadas para trabajar de empleadas en otras ciudades" (participante M8), y estando fuera, se casaron y consiguieron mejores condiciones de vida. Esto no ocurre con lo masculino, pues su simbología alude a una figura viril y machista que no llama la atención de las mujeres no manabitas. Puesto que "a la mujer de afuera no le gustan los hombres manabas porque son mujeriegos" (participante M7), y "los hombres que salen de Manabí, no lo hacen por casarse sino para para buscar trabajo" (participante M4).

Eso se evidencia en la figura 7, en la que la mujer como símbolo sostiene el arquetipo femenino al que se refieren los colaboradores. Las características y atributos de estas se destacan bajo tonos sexistas y se hacen visibles en la cotidianeidad social y en los medios de comunicación, por medio de normas naturalizadas en la publicidad y promovidas en los orígenes imprecisos del falogocentrismo y del mito del dominio masculino (Moore, 1991).

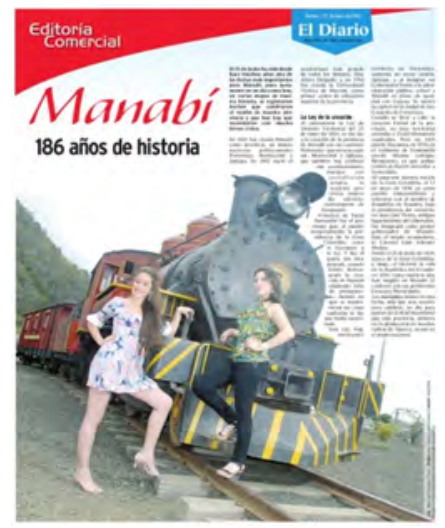

Figura 7. Manabí 100 años de historia. Tomada de: Diario Manabita - Ecuador https://issuu.com/eldiarioec/docs/provincializacion 
En esos ámbitos, se observa una gran cantidad de imágenes publicitarias que colocan a la mujer como estrategia de consumo de forma tácita, tal como se hace metafóricamente en la promoción de otros productos en los centros de consumo y abastecimiento. Respecto a esto, un colaborador menciona que en realidad las mujeres necesitan ser vistas, porque "la mercadería que se no se exhibe no se vende" (participante M10). Y eso en el imaginario manabita propicia un estigma alrededor de las mujeres y hombres solteros, porque se cree que todos deben unirse en convivencia y formar familias.

Posteriormente, se desprende la representación de las mujeres de Chone (ver figura 2) como arquetipo de análisis. En este grupo categorizado en función del origen, las mujeres son etiquetadas con esas características que enunciábamos sobre un ideal de belleza blanqueado, como resultado de la influencia colonial y de los procesos migratorios que se dieron en la costa ecuatoriana posterior a la II Guerra Mundial. Las pieles blancas, los ojos verdes 0 azules y cabellos rubios son a primera vista, las condiciones con las que un gran número, pero no todas las mujeres de este cantón de Manabí se identifican. Esto ha generado que la mujer de esa zona, y no de la costa pacífica (con otras características físicas), capten la atención de una población masculina que, por medio de los imaginarios y sus estereotipos, se ven atraídos para relacionarse con ellas.

"Cualquier hombre quisiera casarse con una mujer bonita y buena esposa" (participante E4).

"En Manabí se pueden conseguir mujeres guapas, cuando un hombre se casa o se amarra con una manaba es motivo de orgullo" (participante E9). 


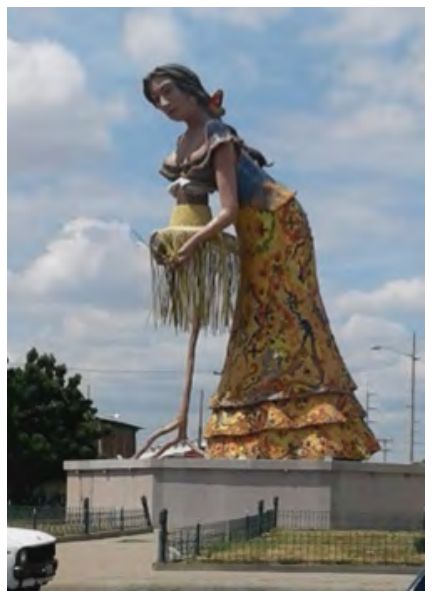

Figura 8. Monumento a la Tejedora Manabita. Tomada de: Gobierno Provincial de Manabí http://www.manabi.gob.ec/222-galeriafotografica-marzo-2010-2.html/baile-folclor-manabita-3

La figura 8 da cuenta de un monumento en la localidad de Montecristi que representa el homenaje que se le hace a la mujer "Tejedora Manabita", encargada de tejer el sombrero de Paja Toquilla ${ }^{8}$. En las entrevistas pudimos conocer que hay quienes consideran que las caracteristicas físicas de este personaje no coinciden con la simbología de las mujeres oriundas esa zona. Pues, en el imaginario colectivo, se las simboliza con estatura mediana y delgada, "la mujer de pile es de piel trigueña, estatura baja, ojos rasgados, y no muy delgada" (participante M7). Para estos colaboradores, este monolito femenino "debió haber sido pensado en la mujer autóctona de Montecristi" (participante M1). Por ende, "no representa a la mujer, lo que más resalta del monumento de la tejedora es el pecho de la mujer y su trasero" (participante E9). Otras aportaciones, en cambio, van en el sentido laboral, pues señalan que la postura de la mujer en el monumento no refleja a plenitud el oficio de tejer y contradice las técnicas ancestrales utilizadas para realizar el oficio, "yo he visto a la mujer que teje sentada en el piso tejiendo o secando la paja, el monumento solo representa una parte del proceso del tejido, eso debería explicarse" (participante M4), porque proyecta solo una parte del trabajo. Pero, en todo caso, también 
hay quienes se identifican con esta representación, porque se trata de una figura femenina relevante en el desarrollo productivo de una profesión importante para la historia, la cultura y la economía de Ecuador.

\section{Conclusiones}

Las representaciones sociales reducen a sus habitantes a identidades esencialistas, determinadas en categorías como casa - sutileza 0 amor propio- y calle -la fuerza laboral y física-. Las cuales responden en este estudio a hechos reconfigurados confrecuencia respecto a lo que se piensay se dice en esos entornos de lo femenino y lo masculino, dando forma a un conjunto de imaginarios que reafirman la injusticia social, bloquean y sentencian a un colectivo a un destino heredado cultural y socialmente. En estos contextos la representación simbólica, más allá de fijar imágenes positivas o negativas, se antepone como hecho a priori, se constituye en un riesgo muy real, y muchas veces en destino (Jung, 1991), condensandoalos prototiposenideales de belleza subjetiva, puesto que la realidad evoca una población mestiza, cuyo origen es tan diverso y tan dinámico como todos los rostros. Por ende, la influencia de las culturas ancestrales, las recientes y las híbridas tienen cabida. No obstante, no podemos escapar por preguntarnos qué ocurre en los bordes, ¿dónde no es posible encontrar ese canon de belleza?, ¿dónde quedan y cómo viven quienes no cumplen con el requisito social de ser un buen manabita?, ¿qué pasa con las mujeres que no son amas de casa, madres y que estudian?, ¿y con los hombres que cambian el agro por trabajos que difieren de la tradición y la historia? Por tanto, estas prácticas naturalizadas continúan interiorizadas en un accionar social que impide repensar la sociedad. En ese sentido, al decir de Lacoste Dujardin (1993), se debe

tratar de analizar todo lo que se les transmite e inculca, las costumbres que deben adquirir, todo lo que determina su comportamiento, orienta sus aptitudes y las dispone a desempeñar un papel determinado con arreglo a la cultura y a los imperativos sociales (p. 58). 
Son estas realidades fijas, interpretadas como comunidades peligrosas que en su sentido más general necesitan "traducirse en cambios conductuales en la vida social y familiar" (Hardy y Jiménez, 2001, p. 86) mirando los espacios sociales (Sarmiento, 1991) y culturales como sectores clave para lograr sociedades más equitativas. Porque como está comprobado, la producción de formas culturalmente apropiadas de conducta masculina y femenina actúan en función central de la autoridad social y está mediada por un amplio espectro de instituciones económicas, sociales, políticas y religiosas (Bourque et al.,1996). Por ende, para cambiar esa realidad, se debe realizar un trabajo articulado entre la sociedad, el estado y la academia para integrar en sus planes y proyectos la perspectiva de género.

Porque claro está que acudir a la resignificación para no encarcelar a sus integrantes en la heteronormatividad es la mejor vía para democratizar los cuerpos y las identidades de mujeres y hombres en la provincia. La lucha por desmantelar las estructuras de desigualdad - estereotipos y prejuicios- el primero como producto y el segundo como reproducción, por dejar de idolatrar a un personaje manabita ligado al campo, al machete, al sudor y al machismo 0 a un ideal de belleza, de esposa, madre o hija, representa el siguiente paso para alcanzar esas sociedades más justas, para ello se necesita "una verdadera conversión colectiva de las estructuras mentales, no sólo[sic] entre los miembros del sexo dominado sino también entre los miembros del sexo dominante, que no pueden contribuir a la liberación más que librando la trampa del privilegio" (Bourdieu, 1996, p. 92).

Estas conclusiones dejan entrever un destino cultural femenino y masculino, interpretado por símbolos y características elegibles en el mercado falogocentrista, pero que siempre puede ser re direccionado hacia una sociedad basada en una educación ciudadana que nos permita interrelacionarnos interpersonal e intragrupalmente por medio de unjuego de emociones que nos haga crecer como seres humanos y colectivos sociales (Fernández-Poncela, 2017). Eso como motivo principal para mejorar las condiciones de vida en comunidad, sobre la base de una sociedad que no estereotipe la diversidad humana con viejas e innecesarias connotaciones ni en función del sexo, ni de la historia de las poblaciones. Y que reconozca la hibridación cultural (Canclini, 2017) y la pers- 
pectiva de género como parte de una realidad innegable que necesita varias miradas para solucionar problemas diversos, pues responde en sí a un cúmulo de muchos géneros diferentes (Butler, 2007), y que, por tanto, no pueden ser parte de un mismo canon social.

\section{Conflicto de intereses}

Los autores declaran la inexistencia de conflicto de interés con institución 0 asociación de cualquier índole.

\section{Referencias}

Bedia, R. (2005). El género en las ciencias sociales. Cuadernos de Trabajo Social, 18, pp. 248-258. Recuperado de https://revistas.ucm.es/index. php/CUTS/article/view/CUTS0505110249A

Bourdieu, P. (1999). Violencia simbólica y luchas políticas. Barcelona, España: Editorial Anagrama, 1999.

Bourdieu, P. (1996). La dominación masculina. La Ventana. Revista de Estudios de Género, (3), 8-94. doi:10.32870/lv.v0i3.2683

Bourque, S. C., Butler, J., Conway, J. K., Cucchiari, S., Lamas, M., Ortner, S. B., Whitehead, H. (1996). El concepto de género. En M. Lamas (Comp.), El género. La construcción de la diferencia sexual (pp. 21-33). Recuperado de https://www.legisver.gob.mx/equidadNotas/publicacionLXIII/ El\%20genero.\%20La\%20construccion\%20cultural\%20de\%20la\%20 diferencia\%20sexual.pdf

Butler, J. (2007). El género en disputa: el feminismo y la subversión de la identidad. Buenos Aires, Argentina: Paidós. 
Canclini, N. (2017). Culturas híbridas, poderes oblicuos. México: Editorial Grijalbo.

Carabí, À., \& Armengol, J. (2008). (Eds.). Debating masculinity (Vol. 91). New York: Icaria Editorial.

Connell, R. (1995). Masculinities. California: Berkeley.

Connell, R. (2002). Gender Short Introductions. Sydney: Polity Press.

Cusme, A. (2012). La oralidad de Manuel Rendón Solórzano y Dumas Heraldo Mora Montesdeoca y la concepción de la mujer en sus creaciones, la décima y el amorfino (Tesis de Maestría), Universidad Andina Simón Bolívar, Ecuador.

De Dios-Vallejo,D. (2014). Equidad de géneroy embarazo. Perinatología y reproducción humana, 28(2), 71-78. Recuperado de http://www.scielo.org. $\mathrm{mx} /$ scielo.php?script=sci_arttext\&pid=S0187-53372014000200002

De la Cuadra, J. (2004). Doce Relatos, Los Sangurimas (2da ed.). Quito, Ecuador: Libresa.

Dietz, G. (1999). Etnicidad y cultura en movimiento: desafíos teóricos para el estudio de los movimientos étnicos. Nueva antropología, XVII(56), 81-107. Recuperado de https://www.redalyc.org/articulo.oa?id=15905606

Do Mar Pereira, M. (2012). Fazendo género no recreio: a negociação do género em espaço escolar. Imprensa de Ciências Sociais.

Durand, G. (2004). Las estructuras antropológicas del imaginario. Introducción a la Arquitepología general. México: FCE Fondo de Cultura Económica.

Durkheim, E. (1912). Las formas elementales de la vida religiosa. Madrid: Akal.

Eisenstein, Z., Sefchovich, S., \& Mastrangelo, S. (1980). Patriarcado capitalista y feminismo socialista. Siglo XXI. 
Ellis, C., \& Berger, L. (2003). Their story/my story/our story: Including the researcher's experience in interview research. Postmodern interviewing, 157-183.

E. E., \& Trujillo. (s/f). El Montubio: Un mestizo-descendiente. Spondylus, (3),1-5.

Federici, S. (2004). Calibán y la bruja: mujeres, cuerpo y acumulación originaria. Madrid: Traficantes de Sueños.

Fernández-Poncela, A. M. (2017). Representaciones sociales estudiantiles: expectativas, evaluaciones y emociones. Revista iberoamericana de educación superior, 8(21), 190-217. Recuperado de http://www.scielo.org. $\mathrm{mx} /$ scielo.php?script=sci_arttext\&pid=S2007-28722017000100190

Flores, J., Gómez, G., y Jiménez, G. (1999). Metodología de la investigación cualitativa. Málaga: Aljibe.

Garay Arellano, E. (2010). El montubio: un mestizo-descendiente. Revista cultural Spondylus, 23, 5-17.

García Peña, A. L. (2002). Historia de las mujeres del siglo XIX: algunos problemas metodológicos. Editorial Universidad Autónoma Metropolitana.

García Peña, L. (2012). Nociones esenciales para el análisis de los símbolos en los textos literarios. 452 F. Revista de teoría de la literatura y literatura comparada, (6), 124-138. Recuperado de http://www.452f.com/pdf/ numero06/06_452f-mis-lilia-leticia-garcia-peña-orgnl.pdf

Geertz, C. (1973). The interpretation of cultures (Vol. 5019). New York: Basic books.

Giraldo, A. (1961). Imagen, símbolo y arquetipo. Revista Colombiana de Psicología, 6(2), 131-147. Recuperado de https://revistas.unal.edu.co/index. php/psicologia/article/view/32611

Gómez Mieles, V.,y Román Cao, E. (2018). La violencia de género en los espacios públicos. Una mirada desde la Universidad Manabita. Atenas, 1(45), 83-98. 
Gratacós, M. (2017). Arquetipos de Jung: definición, características y tipos. Recuperado de https://www.lifeder.com/arquetipos-de-jung/

Guber, R. (2019). La etnografía: método, campo y reflexividad. Buenos Aires: Siglo XXI editores.

Guerrero, P., Ferraro, E., y Hermosa, H. (2016). El trabajo antropológico. Quito: Editorial UPS.

Guil Bozal, A. (1999) El papel de los arquetipos en los actuales estereotipos sobre la mujer. Comunicar,12, 95-100. doi:10.3916/C12-1999-14

Hardy, E., y Jimenez, A. (2001). Masculinidad y Género. Revista Cubana de Salúd Pública, 27(2), 77-88. Recuperado de http://scielo.sld.cu/scielo. php?script=sci_arttext\&pid=S0864-34662001000200001

Hobsbawn, E., \& Ranger, T. (2002). La invención de la tradición. Barcelona: Crítica.

INEC. (2010). Informe Censal Nacional. Resultados de Manabí. Recuperado de http://www.ecuadorencifras.gob.ec/wp-content/descargas/Manulateral/Resultados-provinciales/manabi.pdf

Jung, C. (1991). Los arquetipos y lo inconsciente colectivo. Barcelona, España: Paidós.

Jung, C., y Kerényi, K. (2004). Introducción a la esencia de la mitología. Madrid, España: Siruela.

Lacoste-Dujardin, C. (1993). Las madres contra las mujeres: patriarcado y maternidad en el mundo árabe. España: Universitat de València.

Lamas, M. (1996). El género: la construcción cultural de la diferencia sexual. México: SIDALC.

Lévi-strauss, C. (1985). Las estructuras elementales del parentesco (2). Barcelona: Planeta-Agostini. 
Lorber, J. (2009). Gender Inequality: Feminist theories and politics, 3 Ed. USA: 0xford University Press.

Lucas Meza, G., y Mestre Gómez, U. (2018). Factores jurídicos que condicionan la reincidencia en hogares de Manabí con hechos de violencia intrafamiliar. Mikarimin. Revista Científica Multidisciplinaria, 4(4), 89-104. Recuperado de http://45.238.216.13/ojs/index.php/mikarimin/article/ view/1189/409

Moore, H. (1991). Antropología y Feminismo (3). Madrid, España: Universitat de València.

Munizaga, C., Araya, A., y Rojas, C. (2014). De pescador artesanal a tripulante pesquero. Pesca industrial y transformaciones sociales en Tarapacá. Norte de Chile (1950-1990). Intersecciones en antropología, 15(1), 177185.

Mundó, A. (2015). Elementos metodológicos para el análisis de imágenes. En Actas del XVIII Coloquio de Historia de la Educación: Arte, literatura y educación. Universitat de Vic-Universitat Central de Catalunya, p. 346354.

Nash, M. (2001). Diversidad, multiculturalismo e identidades: perspectivas de género. Barcelona: Ediciones Bellaterra.

Núncio, M. (2008). Mulheres em dupla jornada. A conciliação entre o trabalho e a família. Lisboa: Universidade Técnica de Lisboa e ISCSP.

Pérez, J. (1999). Representaciones sociales de los grupos minoritarios. En Psicología social y trabajo social. McGraw-Hill Interamericana de España.

Puga, C. (2012). El chigualo Manabita, la fiesta Navideña Montubia, Picoazá 2010. (Tesis de Pregrado), Universidad de Cuenca, Ecuador.

Quijano, A. (2003). Notas sobre "Raza" y democracia en los países andinos. Revista Venezolana de Economía y Ciencias Sociales, (9) 53-59. 
Regalado, L. (2018). Identidad cultural local y desarrollo endógeno. La arqueología y la historia en los estudios de identidad cultural manabita. De arqueología hablamos las mujeres, 29- 42.

Rivera Cusicanqui, S. (2010). Ch'ixinakax utxiwa. Una reflexión sobre prácticas y discursos descolonizadores. . Argentina: Ediciones Tinta Limón.

Romão, I. (1989). Distorçôes sexistas nos materiales pedagógicos: como identificá-los e evitá-los. Lisboa: Comissão da Condição Feminina.

Sacaluga, C. (2013). Publicidad: Simbología de masas. Gerona, España: Editorial Planeta Alvi.

Sarmiento, S. (1991). Movimientos Indígenas y participación política. En A. Warman y A. Argueta (Coords.), Nuevos enfoques para el estudio de las étnias indígenas en México. México UNAM - CIIH, pp.387-424.Scott, J. (2008). Género e historia. México, D. F.: Universidad Autónoma de México. Fondo de Cultura Económica.

Tavares, M. (2012). Feminismos: percursos e desafíos. Lisboa, Portugal: Leya.

Tubay, F. (2019). Estereotipos de género:Perspectivas en profesionesartesanales de Portugal. Revista Estudios Feministas, 27(2). doi:10.1590/18069584-2019v27n254182

Tubay Zambrano, F. M. (2020). The semantic crisis of the mother tongue and its imaginaries in capitalist societies. Revista Publicando, 7(23), 24-34. Recuperado de https://revistapublicando.org/revista/index.php/crv/ article/view/2042

UNESC0. (2012). Tejido Tradicional del Sombrero de Paja Toquilla. Recuperado de https://ich.unesco.org/es/RL/tejido-tradicional-del-sombreroecuatoriano-de-paja-toquilla-00729

Villavicencio, L. (2013). Tradición de la cultura montubia en Manabí. (Tesis de pregrado) Universidad San Francisco de Quito, Ecuador. 
Viteri, L. (2016). Políticas públicas ecuatorianas ante las recomendaciones de la CEDAW. Estudio de caso en la Parroquia Rural San Isidro, Provincia Manabí (tesis de maestría), Quito, Ecuador.

Weber, M. (1978). Economy and society: An outline of interpretive sociology. (Vol. 1). México: Fondo Económico de Cultura.

Winker, G., \& Degele, N. (2011). Intersectionality as multi-level analysis: Dealing with social inequality. European Journal of Women's Studies, 18(1), 5166. doi:10.1177/1350506810386084 